\title{
Experimental Investigation of Mechanical Properties of PVC Polymer under Different Heating and Cooling Conditions
}

\author{
Sarkawt Rostam, Alan Kareem Ali, and Firdaws Haidar AbdalMuhammad \\ Department of Production Engineering and Metallurgy, Technical College of Engineering, Sulaimani Polytechnic University, \\ Sulaimani, Kurdistan Region, Iraq \\ Correspondence should be addressed to Sarkawt Rostam; sarkawt.rostam@spu.edu.iq
}

Received 27 November 2015; Accepted 13 January 2016

Academic Editor: Sheng-Rui Jian

Copyright (C) 2016 Sarkawt Rostam et al. This is an open access article distributed under the Creative Commons Attribution License, which permits unrestricted use, distribution, and reproduction in any medium, provided the original work is properly cited.

\begin{abstract}
Due to a widely increasing usage of polymers in various industrial applications, there should be a continuous need in doing research investigations for better understanding of their properties. These applications require the usage of the polymer in different working environments subjecting the material to various temperature ranges. In this paper, an experimental investigation of mechanical properties of polyvinyl chloride (PVC) polymer under heating and cooling conditions is presented. For this purpose standard samples are prepared and tested in laboratory using universal material testing apparatus. The samples are tested under different conditions including the room temperature environment, cooling in a refrigerator, and heating at different heating temperatures. It is observed that the strength of the tested samples decreases with the increasing of heating temperature and accordingly the material becomes softer. Meanwhile the cooling environments give a clear increasing to the strength of the material.
\end{abstract}

\section{Introduction}

Among the plastic materials, polyvinyl chloride (PVC) is the one of the most used and produced [1]. For better understanding of the PVC properties and for the proper utilization of the working environment, a considerable number of works can be seen in this field. The range of these attempts covers different aspects of investigations on PVC from experimental investigations [2-7] to modelling and simulation approaches [8].

In spite of poor mechanical properties and processing of PVC, a wide range of products are manufactured by utilization of PVC. In this aspect efforts have been made to improve its property [9]. Different techniques were used by Nowicki et al. [10] to determine the mechanical properties of polymers. The study included the effect of ultraviolet irradiation on the mechanical properties. Deshmukh and Joshi [11] observe an improvement of mechanical properties of PVC as a function of graphene oxide loading. Both tensile strength and Young's modulus were increased as a result of this loading. Mechanical properties of PVC/multilayer graphene were investigated by Wang et al. [12]. The investigation aimed to improve the tensile modulus of PVC.
The effects of both heat treatment and physical ageing on PVC's mechanical properties were examined by Yarahmadi et al. [13]. The temperature below and above the glass transition range was used and the results showed a decrease in elongation at the break point. Bishay et al. [14] investigate the mechanical, electrical, and thermal properties of PVC filled with aluminium powder at temperature range from $30^{\circ} \mathrm{C}$ to $98^{\circ} \mathrm{C}$. Merah et al. [15] address the effect of both temperature and weld line on chlorinated PVC. The effects of temperature range from $-10^{\circ} \mathrm{C}$ to $70^{\circ} \mathrm{C}$ were taken. It is observed that the brittle fracture happened below room temperature while the ductile fracture happened above $23^{\circ} \mathrm{C}$. In a study conducted by Colloca et al. [16], three types of load, namely, tensile, compression, and impact, have been applied to closed-cell PVC foams. It showed that there was a strong relationship between the mechanical properties of elastic modulus and strength with PVC foams' density. Sarfraz et al. [17] used controlled uniaxial stretching to improve the tensile properties of PVC-montmorillonite nanocomposites at a temperature of $80^{\circ} \mathrm{C}$. The improvement is shown by determining stressstrain curve and X-ray diffraction for both unstretched and stretched films. Accordingly the improvement imparted an increase in Young's modulus and tensile strength of the films. 


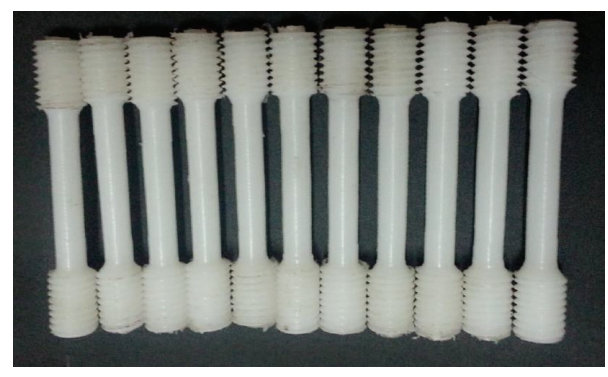

FIGURE 1: PVC samples.

As the polymers are now a good alternative to metals in today's manufacturing world, the above efforts and the current work present in this paper aim to give a clear understanding of the ability of PVC to work safely within the designed loads in the applications where PVC is used.

In this paper, experimental investigation of mechanical properties of PVC samples under different heating and cooling conditions is presented to determine the load and elongation limits and the strength of the tested samples. The remainder of the paper is organized as follows. The experimental work is detailed in Section 2. The section includes two parts. The first part presents the materials used in the experiments and their preparation to standard samples for testing while the second part explains the experimental procedure. Results and discussions are presented in Section 3 followed by conclusion and future works in Section 4 .

\section{Experimental Work}

2.1. Materials. Commercial round bars of PVC were provided with dimensions of $15 \mathrm{~mm}$ diameter and $60 \mathrm{~mm}$ length. The round PVC samples are prepared according to DIN 50125 standards. The samples were machined to M10 threaded heads on both sides with a measuring length of $30 \mathrm{~mm}$ and a diameter of $6 \mathrm{~mm}$. The PVC samples, shown in Figure 1, were machined to the standard dimensions by lathe machine. Eleven samples were prepared for testing.

2.2. Experimental Procedure. The standard PVC samples are divided into three groups for the next step of experimentation. The first group of the samples remain as it is without any heating or cooling. The second group were heated for a period of time to approximately $90^{\circ} \mathrm{C}$ in boiling water. The third group of the samples were cooled in a refrigerator to $-18^{\circ} \mathrm{C}$.

In this work, universal material testing apparatus, Figure 2, was used to demonstrate the basic principles of tensile strength testing. The maximum test force on this apparatus is $20 \mathrm{kN}$.

The apparatus is provided with PC-aided measurement data acquisition system to record and evaluate the measuring data. The load is applied gradually to the clamped specimen until rapture as shown in Figure 3.

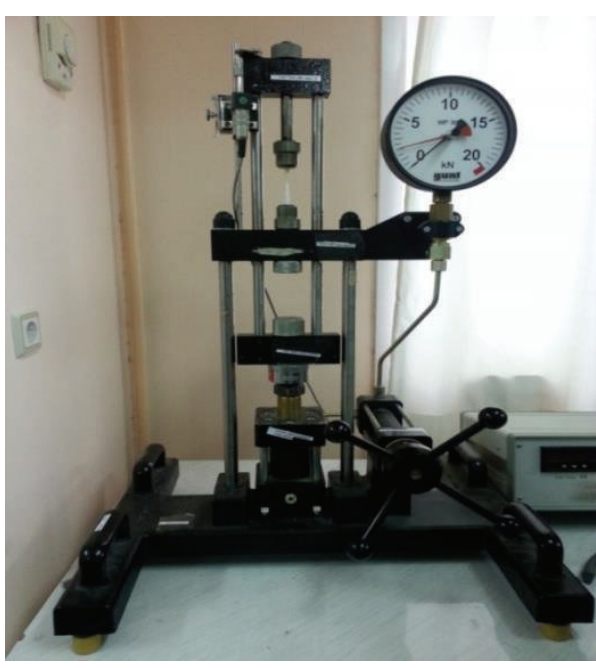

FIGURE 2: Universal material testing apparatus.

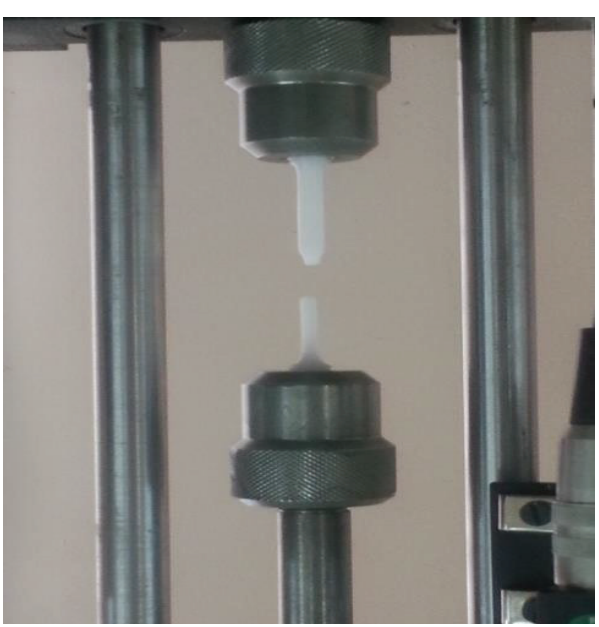

Figure 3: Ruptured specimen.

TABLE 1: Range of the applied loads.

\begin{tabular}{lc}
\hline Load range $(\mathrm{kN})$ & Working environment \\
\hline $1.8-1.88$ & Room temperature \\
$1.92-2.07$ & Cooled samples (to $-18^{\circ} \mathrm{C}$ ) \\
$0.6-1.5$ & Heated samples (to approximately $90^{\circ} \mathrm{C}$ ) \\
\hline
\end{tabular}

\section{Results and Discussion}

The aim of this research work is to monitor and find the tensile strength of PVC bars under a load at various working environments as well as the load-elongation limits for each condition. Table 1 shows the range of the applied load during experiments for different working environments.

Figure 4 shows the relationship between force and elongation for PVC specimen tested without heating or cooling conditions. It can be seen from the figure that the recorded maximum applied load was $1.8 \mathrm{kN}$ and the sample has 


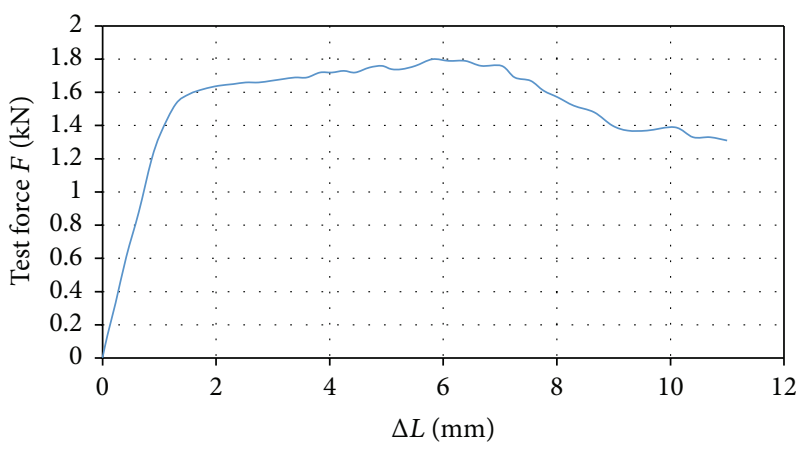

FIGURE 4: Force-elongation diagram.

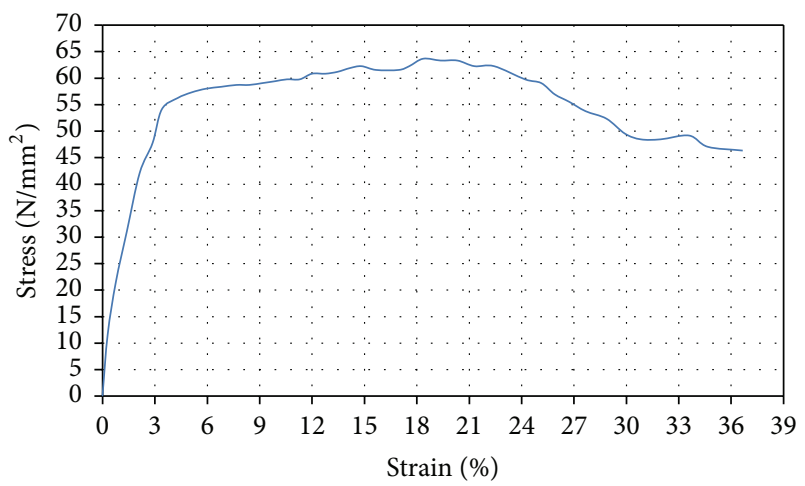

FIGURE 5: Stress-strain diagram.

been ruptured (failure of the sample) at $1.3 \mathrm{kN}$ with $11 \mathrm{~mm}$ elongation.

The tensile strength of the tested PVC samples can be calculated from the following formula:

$$
\text { Tensile strength }=\frac{\text { Maximum test force }}{\text { Cross-section area of the sample }} \text {. }
$$

For the sample under investigation the tensile strength is equal to $63.67 \mathrm{~N} / \mathrm{mm}^{2}$ as shown in Figure 5. The figure also shows the stress at the failure point which is recorded as $46.33 \mathrm{~N} / \mathrm{mm}^{2}$.

In Figure 6 the force-elongation diagram is shown, where the PVC specimen is heated to approximately $90^{\circ} \mathrm{C}$. The figure shows the diagrams for two different temperatures $64^{\circ} \mathrm{C}$ and $90^{\circ} \mathrm{C}$, respectively. For the sample heated to $64^{\circ} \mathrm{C}$, the maximum testing force and failure force are $1.5 \mathrm{kN}$ and $1.32 \mathrm{kN}$, respectively, corresponding to $18.39 \mathrm{~mm}$ elongation at fracture point. Increasing the heating temperature, for instance, to $90^{\circ} \mathrm{C}$, of the PVC samples causes a decreasing of the amount of the testing forces at both the maximum point and the failure point as shown in the figure.

Corresponding to the results above, Figure 7 shows the stress-strain diagram for PVC samples at different heating temperatures.

Interesting remarks regarding the force and elongation can be seen in Figure 8. The figure shows that the maximum testing force has been recorded for the cooled sample while

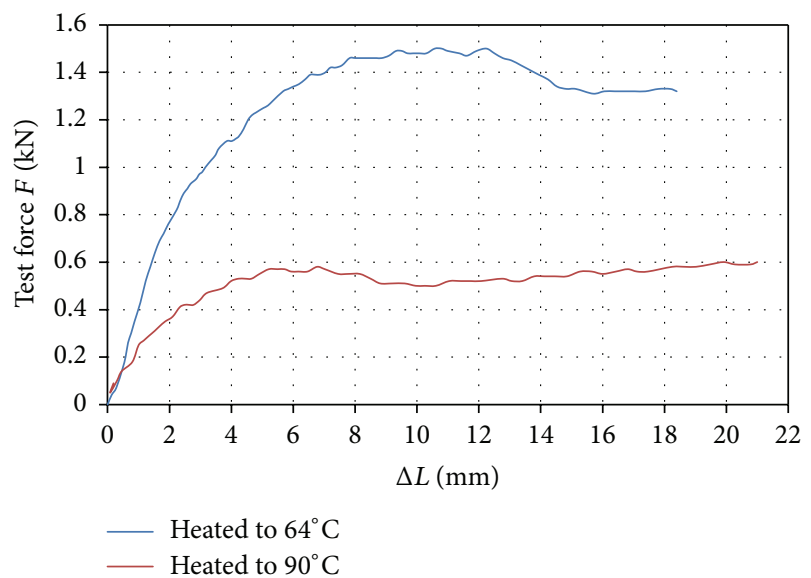

FIGURE 6: Force-elongation diagrams at different heating temperatures.

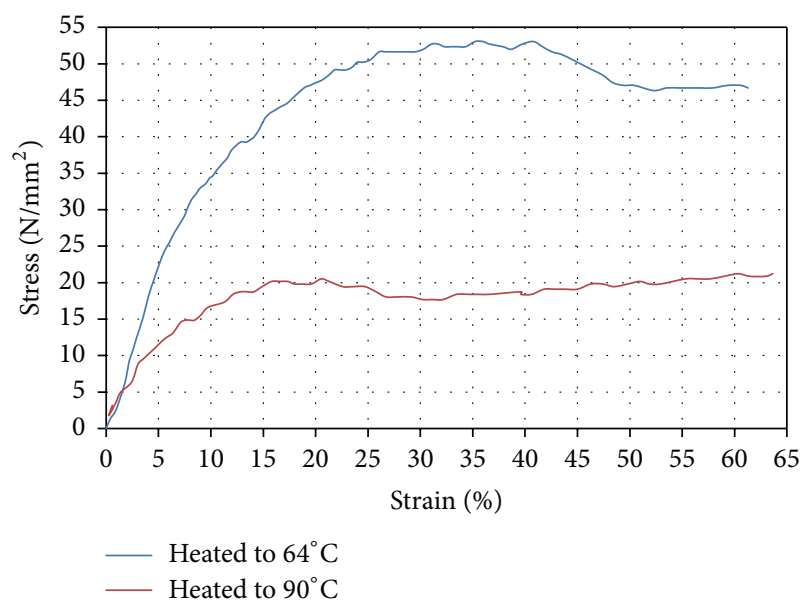

FIGURE 7: Stress-strain diagram for heated samples.

the least force has been recorded for the heated sample to $90^{\circ} \mathrm{C}$.

From the series experiments conducted on the prepared PVC samples tested at different working environments, Table 2 has been drawn. It can be concluded from the table that the cooled sample has the maximum testing force $(2.1 \mathrm{kN})$ while the minimum failure force $(0.6 \mathrm{kN})$ has been recorded for the heated sample to $90^{\circ} \mathrm{C}$.

To get a clear view of the strength for the tested samples, the stress-strain diagram is drawn as shown in Figure 9. The exact numerical values of the tensile strength for each tested specimen are given in Table 3. It can be noted from the table that the maximum strength is for the cooled specimen and the minimum strength is for the heated sample to $90^{\circ} \mathrm{C}$.

\section{Conclusions}

In this research, an experimental investigation for the effect of various heating and cooling environments on the mechanical behavior of PVC polymers was presented. For this purpose, three groups of standard PVC samples were prepared using 
TABLE 2: Force and elongation data for different working environments.

\begin{tabular}{lcccc}
\hline Working environment & Max. test force, $\mathrm{kN}$ & Elongation, $\mathrm{mm}$ & Failure force, $\mathrm{kN}$ & 1.3 \\
Free condition & 1.8 & 5.81 & 1.32 & 11 \\
Heated to $64^{\circ} \mathrm{C}$ & 1.5 & 10.57 & 0.6 & 18.39 \\
Heated to $90^{\circ} \mathrm{C}$ & 0.58 & 6.77 & 1.69 & 21 \\
Cooled samples & 2.1 & 5.85 & 8.8 \\
\hline
\end{tabular}

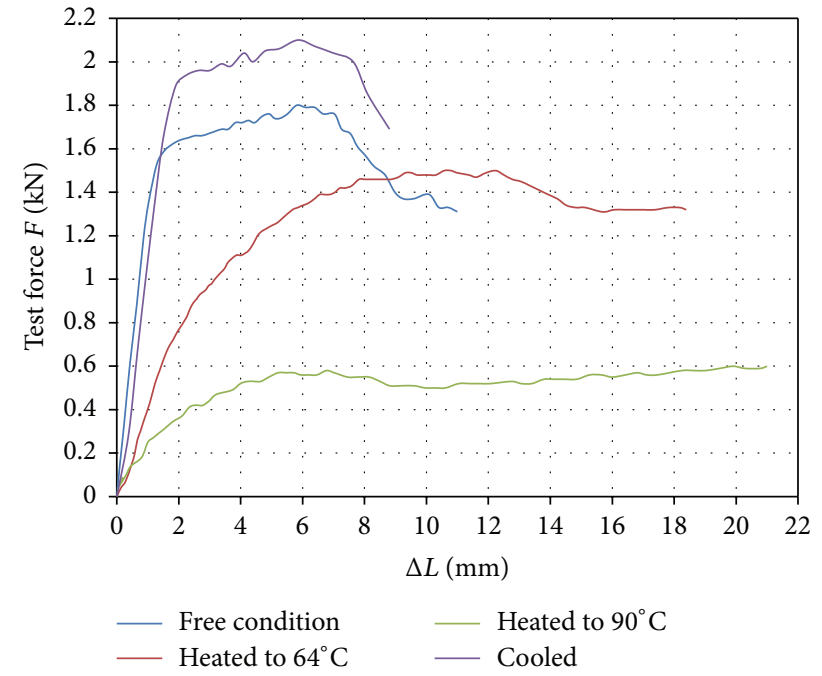

FIGURE 8: Force-elongation diagrams at different working environments.

TABLE 3: Tensile strength data for different working environment.

\begin{tabular}{lcc}
\hline Working environment & $\begin{array}{c}\text { Strength, } \\
\mathrm{N} / \mathrm{mm}^{2}\end{array}$ & Corresponding strain (\%) \\
\hline Cooled sample & 74.27 & 19.5 \\
Free condition & 63.67 & 18.3 \\
Heated to $64^{\circ} \mathrm{C}$ & 53.05 & 35.9 \\
Heated to $90^{\circ} \mathrm{C}$ & 20.51 & 20.5 \\
\hline
\end{tabular}

lathe machine and tested using universal material tester. The apparatus was used to apply load until the fracture of the specimen. Different load ranges have been used depending on the working environment during the experiments. The samples were heated and cooled to different conditions as follows:

(i) Heating temperature from $64^{\circ} \mathrm{C}$ to $90^{\circ} \mathrm{C}$.

(ii) Cooling temperature to $-18^{\circ} \mathrm{C}$.

From the results, it can be concluded that

(i) the heating conditions for PVC samples make both the force and the strength smaller than the normal temperature condition;

(ii) the heating conditions make the samples softer;

(iii) the cooled condition showed the need of larger load to rupture the specimen; that is to say, the PVC samples became brittle behavior polymer.

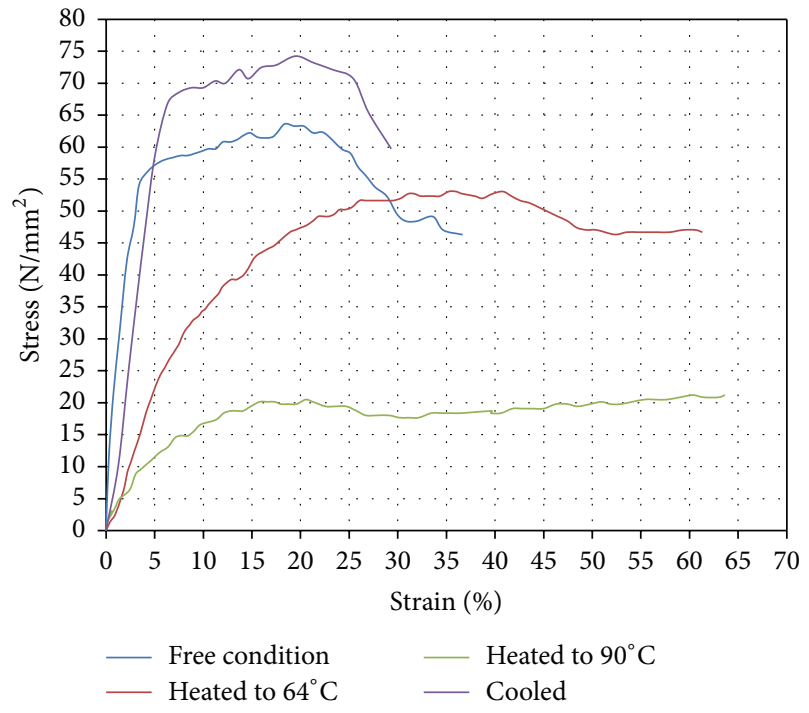

FIGURE 9: Stress-strain diagrams at different working environment.

The current work can be expanded in several directions. One direction is to expand the experiments by conducting other tests such as fatigue and impact tests. Another direction is to demonstrate the scanning electron microscope (SEM) photographs for the tested specimens and the thermal transition analysis for different working environments.

\section{Conflict of Interests}

The authors declare that there is no conflict of interests regarding the publication of this paper.

\section{Acknowledgments}

The authors would like to acknowledge the Mechanical Workshop staff and Engineer Barzan Akram Hama Saeed from the Strength of Materials' Lab, Department of Production Engineering and Metallurgy, for their assistance during the experiments.

\section{References}

[1] K. Mulder and M. Knot, "PVC plastic: a history of systems development and entrenchment," Technology in Society, vol. 23, no. 2, pp. 265-286, 2001.

[2] Q. Liao, J. Huang, T. Zhu, C. Xiong, and J. Fang, "A hybrid model to determine mechanical properties of soft polymers by nanoindentation," Mechanics of Materials, vol. 42, no. 12, pp. 1043-1047, 2010. 
[3] P. Kurkcu, L. Andena, and A. Pavan, "An experimental investigation of the scratch behaviour of polymers: 1 . Influence of ratedependent bulk mechanical properties," Wear, vol. 290-291, pp. 86-93, 2012.

[4] P. Kurkcu, L. Andera, and A. Pavan, "An experimental investigation of the scratch behaviour of polymers: influence of hard or soft fillers," Wear, vol. 317, pp. 277-290, 2014.

[5] M. Alzeer and K. J. D. MacKenzie, "Synthesis and mechanical properties of new fibre-reinforced composites of inorganic polymers with natural wool fibres," Journal of Materials Science, vol. 47, no. 19, pp. 6958-6965, 2012.

[6] M. Alzeer and K. MacKenzie, "Synthesis and mechanical properties of novel composites of inorganic polymers (geopolymers) with unidirectional natural flax fibres (phormium tenax)," Applied Clay Science, vol. 75-76, pp. 148-152, 2013.

[7] Z. Spitalsky, D. Tasis, K. Papagelis, and C. Galiotis, "Carbon nanotube-polymer composites: chemistry, processing, mechanical and electrical properties," Progress in Polymer Science, vol. 35, no. 3, pp. 357-401, 2010.

[8] A. Shokuhfar and B. Arab, "The effect of cross linking density on the mechanical properties and structure of the epoxy polymers: molecular dynamics simulation," Journal of Molecular Modeling, vol. 19, no. 9, pp. 3719-3731, 2013.

[9] Y. Du, J. Gao, J. Yang, and X. Liu, "Dynamic rheological behavior and mechanical properties and of PVC/ASA blends," Journal of Polymer Research, vol. 19, article 9993, 2012.

[10] M. Nowicki, A. Richter, B. Wolf, and H. Kaczmarek, "Nanoscale mechanical properties of polymers irradiated by UV," Polymer, vol. 44, no. 21, pp. 6599-6606, 2003.

[11] K. Deshmukh and G. M. Joshi, “Thermo-mechanical properties of poly (vinyl chloride)/graphene oxide as high performance nanocomposites," Polymer Testing, vol. 34, pp. 211-219, 2014.

[12] H. Wang, G. Xie, Z. Ying, Y. Tong, and Y. Zeng, "Enhanced mechanical properties of multi-layer graphene filled poly(vinyl chloride) composite films," Journal of Materials Science and Technology, vol. 31, no. 4, pp. 340-344, 2015.

[13] N. Yarahmadi, I. Jakubowicz, and T. Hjertberg, "The effects of heat treatment and ageing on the mechanical properties of rigid PVC," Polymer Degradation and Stability, vol. 82, no. 1, pp. 5972, 2003.

[14] I. K. Bishay, S. L. Abd-El-Messieh, and S. H. Mansour, "Electrical, mechanical and thermal properties of polyvinyl chloride composites filled with aluminum powder," Materials \& Design, vol. 32, no. 1, pp. 62-68, 2011.

[15] N. Merah, M. Irfan-ul-Haq, and Z. Khan, “Temperature and weld-line effects on mechanical properties of CPVC," Journal of Materials Processing Technology, vol. 142, no. 1, pp. 247-255, 2003.

[16] M. Colloca, G. Dorogokupets, N. Gupta, and M. Porfiri, "Mechanical properties and failure mechanisms of closed-cell PVC foams," International Journal of Crashworthiness, vol. 17, no. 3, pp. 327-336, 2012.

[17] A. Sarfraz, M. F. Warsi, M. I. Sarwar, and M. Ishaq, "Improvement in tensile properties of PVC-montmorillonite nanocomposites through controlled uniaxial stretching," Bulletin of Materials Science, vol. 35, no. 4, pp. 539-544, 2012. 


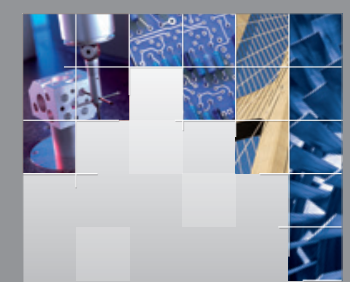

\section{Enfincering}
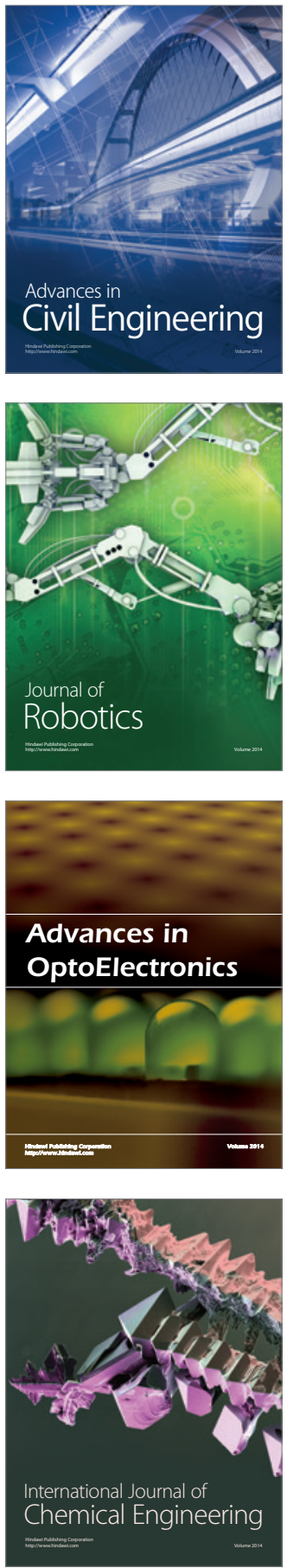

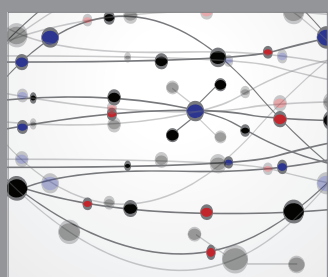

The Scientific World Journal

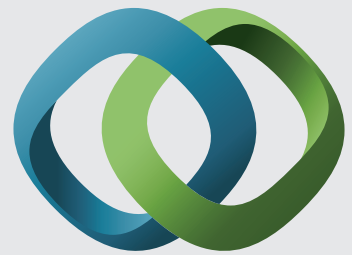

\section{Hindawi}

Submit your manuscripts at

http://www.hindawi.com
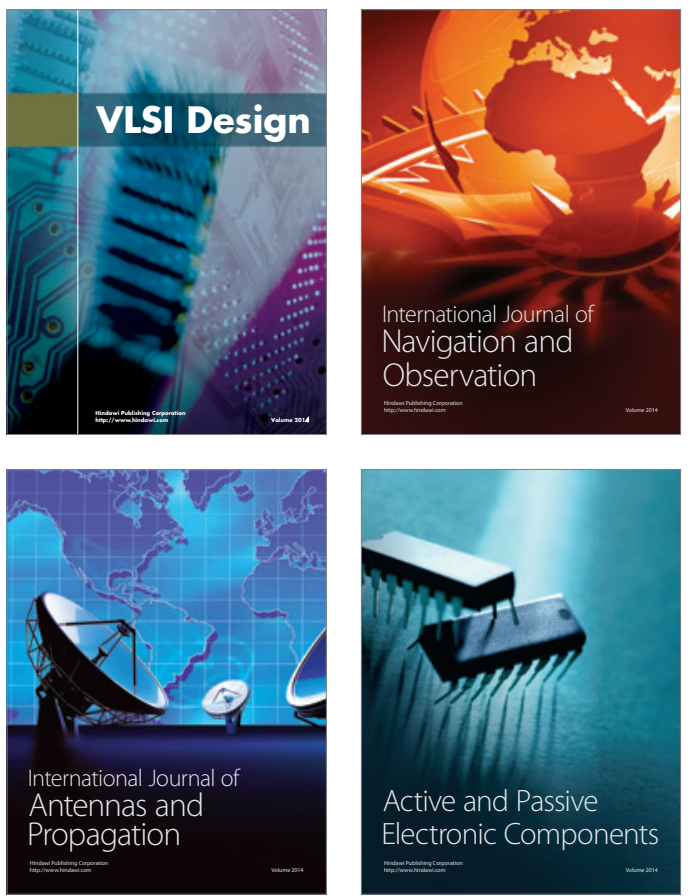
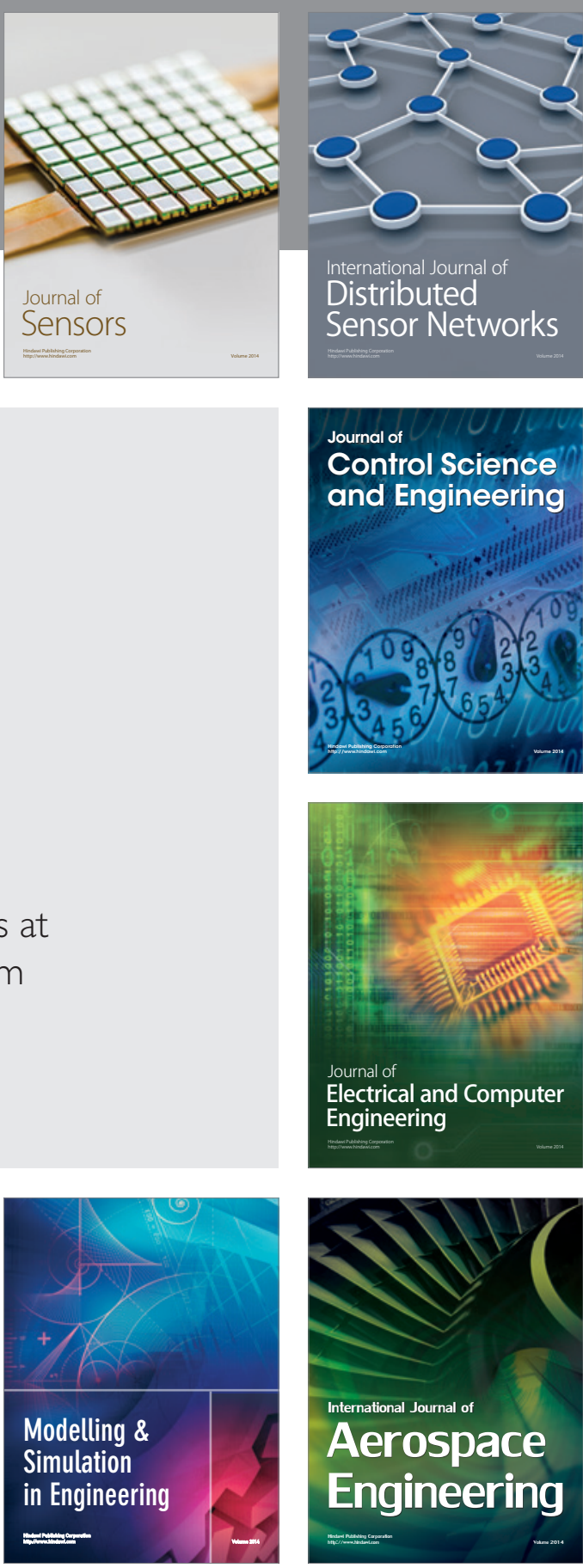

International Journal of

Distributed

Sensor Networks

Journal of

Control Science

and Engineering
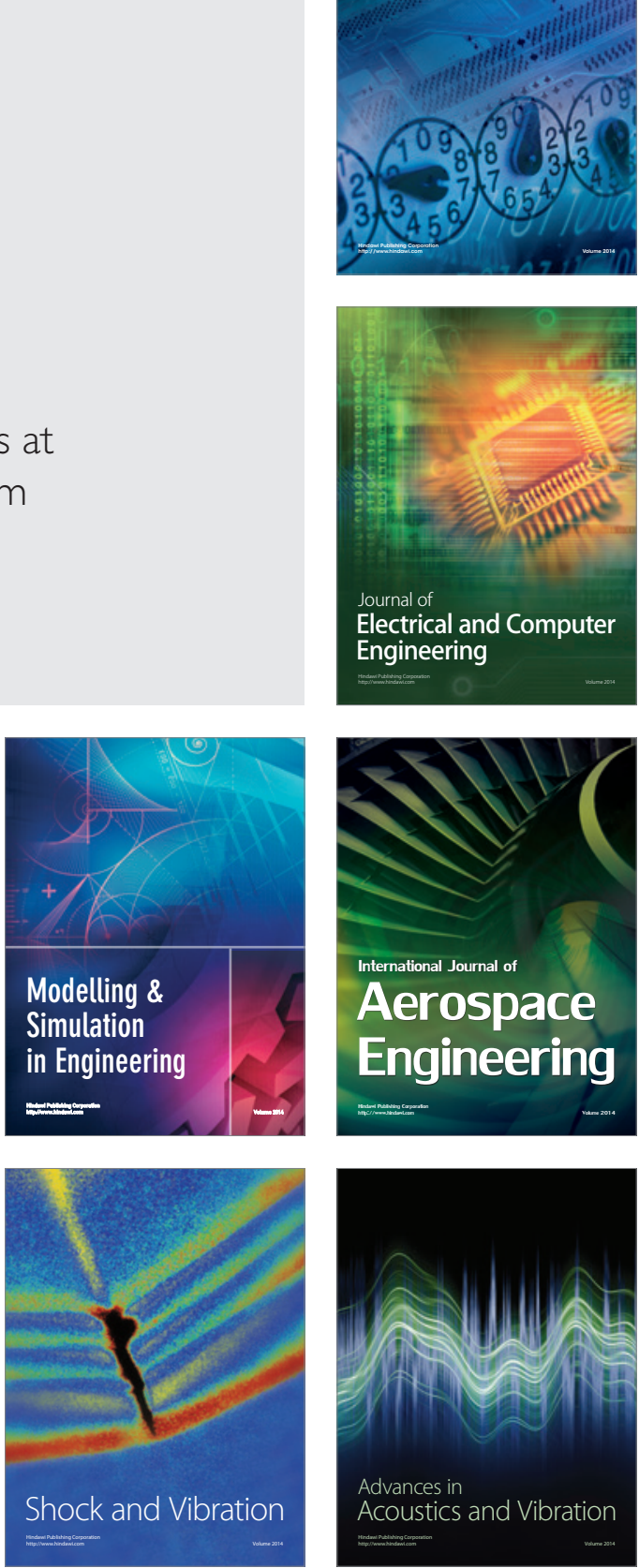